\title{
Sufentanil Sublingual for Acute Post-Operative Pain: A Systematic Literature Review Focused on Pain Intensity, Adverse Events, and Patient Satisfaction
}

\author{
Luca G. Giaccari - Francesco Coppolino - Caterina Aurilio • \\ Valentina Esposito - Maria Caterina Pace - Antonella Paladini • \\ Maria Beatrice Passavanti - Vincenzo Pota - Pasquale Sansone
}

Received: March 10, 2020 / Published online: April 17, 2020

(C) The Author(s) 2020

\begin{abstract}
Context: Pain is commonly experienced among patients after surgical procedures. Clinical pain management after surgery is far from being successful. Patients may control postoperative pain by self-administration of intravenous opioids using devices designed for this purpose (patient-controlled analgesia or PCA). PCA devices have been developed including the sufentanil sublingual tablet system (SSTS). A systematic review of the use of SSTS for postoperative pain is needed to identify an alternative method of pain management.

Objectives: To systematically review literature to establish the efficacy and the safety of PCA with SSTS used in the treatment of moderate-tosevere acute post-operative pain in a hospital setting.
\end{abstract}

Enhanced Digital Features To view digital features for this article go to https://doi.org/10.6084/m9. figshare.12024156.

L. G. Giaccari · F. Coppolino · C. Aurilio ·

V. Esposito - M. C. Pace · M. B. Passavanti - V. Pota .

P. Sansone $(\triangle)$

Department of Woman, Child and General and

Specialized Surgery, University of Campania "Luigi

Vanvitelli", Naples, Italy

e-mail: pasquale.sansone@unicampania.it

A. Paladini

Department of MESVA, University of L'Aquila,

Aquila, Italy
Methods: Embase, MEDLINE, Google Scholar, and Cochrane Central Trials Register were systematically searched in December 2019 for studies examining SSTS for pain in adult after surgical procedures. The methodological quality of the studies and their results were appraised using the Consensus-based Standards for the Selection of Health Measurement Instruments (COSMIN) checklist and specific measurement properties criteria, respectively.

Results: Sixteen studies evaluating SSTS were included for a total of 2311 patients. All participants in the SSTS group reported NRS $\leq 4$ within $24 \mathrm{~h}$ after surgery. Patient satisfaction was high, with a minimum of $70 \%$ satisfaction among patients treated with SSTS. The most common adverse events (AEs) overall for SSTS 15 and $30 \mathrm{mcg}$ were nausea, vomiting, and headache. AEs observed in the studies were generally consistent with those associated with opioids and the postsurgical setting.

Conclusions: SSTS is an important system for the management of moderate-to-severe acute pain in a hospital setting. SSTS is well tolerated, with no unexpected adverse events (AEs) and no clinically meaningful vital sign changes. These data confirm the safety and tolerability of the SSTS. Successful pain management resulted in a high level of acceptance of the SSTS by patients with high satisfaction for the method of pain control. 
Keywords: Adverse events (AEs); Pain intensity; Patient-controlled analgesia (PCA); Patient satisfaction; Post-operative pain; Sufentanil sublingual tablet system (SSTS)

\section{Key Summary Points}

$70 \%$ of these patients experience acute post-operative pain.

Sufentanil sublingual tablet system (SSTS) is a noninvasive route of administration to treat moderate-to-severe acute pain.

Outcomes: pain intensity, adverse events, patient satisfaction.

SSTS is a successful pain management system in a hospital setting.

Safety and tolerability of the SSTS were confirmed.

\section{INTRODUCTION}

\section{Rationale}

More than 234 million major surgical procedures are performed every year worldwide [1] and data suggest up to $70 \%$ of these patients experience moderate-to-severe pain postoperatively [2]. Post-operative pain should be alleviated as soon and as effectively as possible to reduce suffering and to facilitate rapid recovery and mobility, thereby improving patient outcomes [3]. However, clinical pain management after surgery is far from being successful [4]. In a national survey, approximately $80 \%$ of patients experienced acute pain after surgery. Of these patients, $86 \%$ had moderate, severe, or extreme pain. Referring to the numeric rating scale (NRS) pain intensity ratings, we can classify mild pain as $0-4$, moderate pain as $5-6$, and severe pain as $7-10$. Almost $25 \%$ of patients who received pain medications experienced adverse effects. The most common side effects were drowsiness (41\%), nausea (35\%), constipation $(26 \%)$, sleeplessness $(18 \%)$, dizziness $(14 \%)$, vomiting (14\%), abdominal discomfort $(10 \%)$, itching $(10 \%)$, mood changes (8\%), and difficult urination (8\%) [4].

The international guidelines recommended the use of a multimodal analgesia. Analgesic medication and techniques combined with non-pharmacological interventions have additive or synergistic effects and more effective pain relief compared with single-modality interventions [5].

Patients may control postoperative pain by self-administration of intravenous opioids using devices designed for this purpose (patient-controlled analgesia or PCA). PCA shows a number of benefits when compared with non-PCA administration of opioids. These include more effective analgesia, fewer analgesic gaps, and potentially shorter duration of stay in hospital, as well as high levels of patient satisfaction, as they are more in control of their own treatment.

Postoperative guidelines recommend oral over intravenous opioids in patients who can use the oral route [5]. Consequently, PCA devices have been developed including the sufentanil sublingual tablet system (SSTS). In July 2014, the Food and Drug Administration (FDA) approved the opioid analgesic Zalviso ${ }^{\circledR}$ to delivery $15 \mathrm{mcg}$ of sufentanil. In October 2018, the FDA approved the opioid analgesic Dsuvia ${ }^{\circledR}$ to deliver $30 \mathrm{mcg}$ of medical treatment.

The goal was to provide a noninvasive route of administration to treat moderate-to-severe acute pain in non-opioid-tolerant patients, as the current rapidly acting transmucosal opioid analgesic products are approved for opioid-tolerant cancer patients only.

\section{Objectives}

The aim of the current study was to conduct a systematic literature review to establish the efficacy and safety of PCA with SSTS used in the treatment of moderate-to-severe acute post-operative pain in the hospital setting. 


\section{METHODS}

\section{Protocol and Registration}

We performed a systematic review based on preferred reporting items for systematic reviews and meta-analyses (PRISMA) statement [6], and following a protocol written prior to starting the review. This article is based on previously conducted studies and does not contain any studies with human participants or animals performed by any of the authors.

\section{Eligibility Criteria}

The population, intervention, comparison, and outcome (PICO) criteria were applied to the research question. Patients of at least 18 years undergoing major surgical procedures were considered as the population (P); the intervention (I) was postoperative analgesia with SSTS $15 \mathrm{mg}$ or SSTS $30 \mathrm{mg}$; the comparison (C) concept was not applicable to the research question; pain intensity, adverse events (AEs) and patient satisfaction after using SSTS for postoperative analgesia in patients undergoing major surgical procedures were considered the outcomes (O) for this systematic review. We included observational study, clinical trial, and randomized controlled trial published from 2000 to the present.

PICO criteria are summed in Table 1.

Table 1 PICO criteria for including studies

\begin{tabular}{ll}
\hline Population & $\begin{array}{r}\text { Patients of at least } 18 \text { years undergoing } \\
\text { major surgical procedures }\end{array}$ \\
Intervention & $\begin{array}{r}\text { Postoperative analgesia with SSTS } 15 \mathrm{mg} \text { or } \\
\text { SSTS } 30 \mathrm{mg}\end{array}$ \\
Comparator & $\begin{array}{l}\text { No comparator } \\
\text { Outcomes }\end{array}$ \\
$\begin{array}{l}\text { Pain intensity, adverse events, patient } \\
\text { satisfaction }\end{array}$ \\
Study type & $\begin{array}{l}\text { Observational study, clinical trial, } \\
\text { randomized controlled trial }\end{array}$ \\
Time & From 2000 to present \\
\hline
\end{tabular}

\section{Literature Search}

We identified the articles by searching electronic databases (Embase, MEDLINE, Google Scholar, and Cochrane Central Trials Register). Other relevant studies were identified from the reference lists of systematic reviews and metaanalyses.

We used a combination of terms for "sufentanil sublingual tablet system", "post-operative or postsurgical pain", "observational study", "clinical trial", and "randomized clinical trial". We applied no language restrictions in searches. The initial search was performed in December 2019.

The studies included in this review evaluated adult patients clinically diagnosed with moderate-to-severe acute post-operative pain in a hospital setting following any type of surgery.

\section{Primary Outcomes}

The primary outcome was the pain intensity assessed via NRS at 12 and $24 \mathrm{~h}$. Pain intensity data assessed by means other than a 0-10 NRS were normalized to such a scale. Some studies reported the sum of pain intensity difference (SPID) at 12, 24, and $48 \mathrm{~h}$.

\section{Secondary Outcomes}

We extracted data on the following secondary outcomes:

1. Adverse events;

2. Patient satisfaction.

\section{Selection of Studies}

We determined eligibility by reading the abstract of each study identified by the search. We eliminated studies that clearly did not satisfy our inclusion criteria, and obtained full copies of the remaining studies. Two review authors read these studies independently and reached agreement by discussion.

The methodological quality of the included studies was evaluated and rated using the 
COSMIN checklist, which has a four-point rating scale $[7,8]$.

\section{Data Extraction and Management}

Data extracted included the following:

- Age and sex of participants;

- Number of participants enrolled and completing the study;

- Type of operation;

- Pain intensity for all time points at which it was measured;

- PCA settings (bolus dose, lockout, limit dose);

- Patient satisfaction;

- Severity or incidence of adverse events.

\section{RESULTS}

The flow diagram (Fig. 1) shows the results from the literature search and the study selection process. Sixteen studies met the eligibility criteria (see Table 2).

According to the COSMIN checklist, all studies included in this review showed an excellent-to-good quality. The majority of clinical trials had a low risk of bias. Observational studies cannot, by design, offer establish causality through features such as randomization and concealment of allocation. In contrast, threats to validity and precision from performance bias, detection bias, inadequate sample size, and lack of study efficiency did not appear relevant in the study selection.

In the included studies, 2311 patients were treated with SSTS: 1343 females and 821 males (Costa F, 2019 and Lakshman S, 2016 did not reported sex of participants) with mean age of

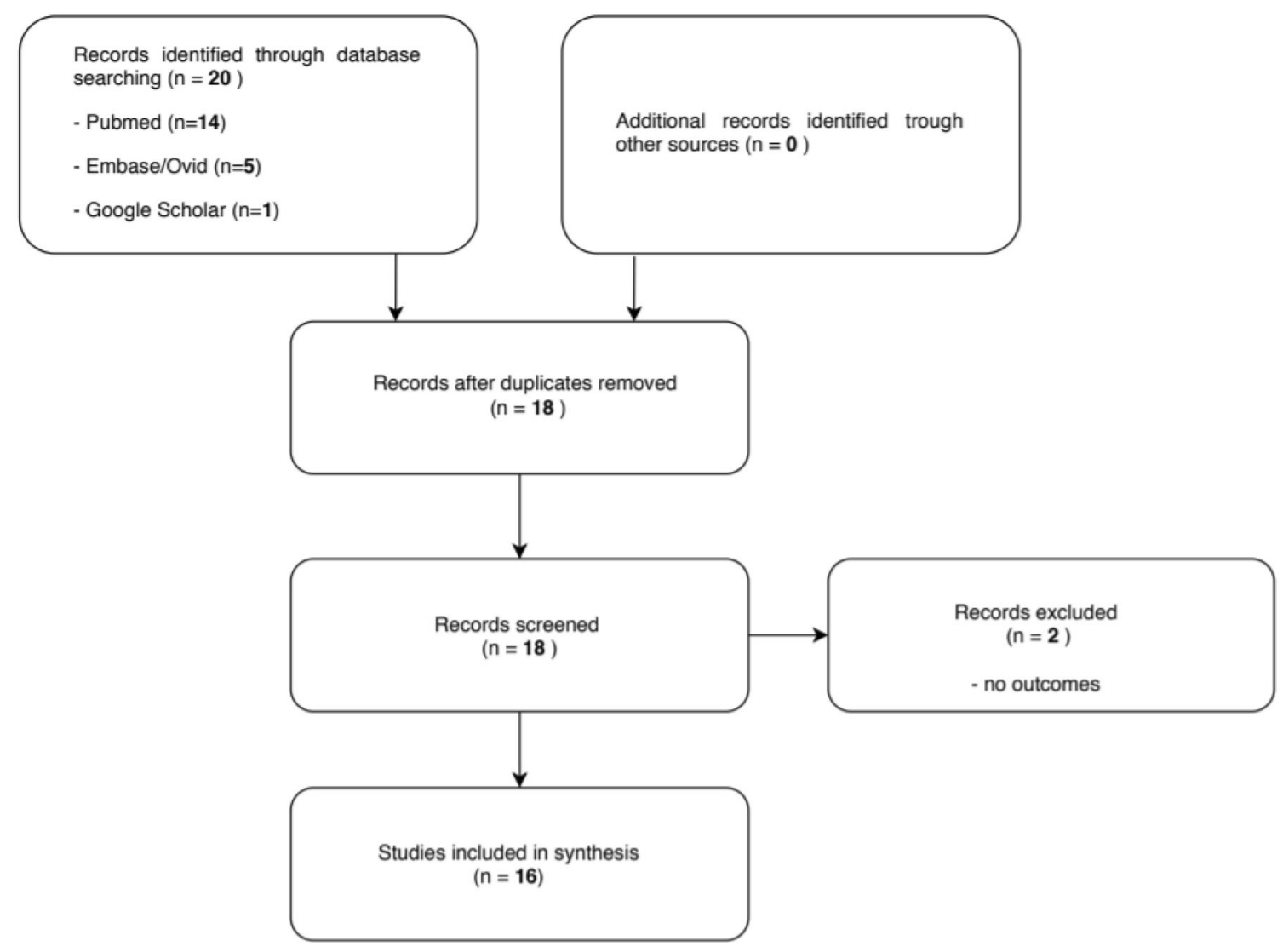

Fig. 1 Flow diagram study selection process 
$55.5 \pm 8.9$ years (Costa F, 2019 did not reported age of participants).

Four studies (Hutchins JL, 2017; Lakshman S 2016; Miner JR, 2018; Minkowitz HS, 2017) evaluated the safety and efficacy of SST $30 \mathrm{mcg}$ for the management of postoperative pain. Other papers evaluated SSTS $15 \mathrm{mcg}$.

The largest study involved 341 patients ( $\mathrm{Po}$ gatzki-Zahn E, 2019), while the smallest consisted of 16 patients (Rispoli M, 2018). All analyzed studies were conducted in inpatient settings.

Patients underwent various operation; the most common surgeries were abdominal procedures (eight studies: Hutchins JL, 2017; Lakshman S, 2016; Meijer F, 2018; Melson TI, 2014; Minkowitz HS, 2017; Pogatzki-Zahn E, 2019; Ringold FG, 2015; Turi S, 2019) and orthopedic surgery (eight studies: Dransart C, 2018; Hutchins JL, 2017; Jove M, 2015; Meijer F, 2018; Melson TI, 2014; PogatzkiZahn E, 2019; Scardino M, 2018; Van Deen DE, 2018), followed by gynecological (three studies: Leykin Y, 2019; PogatzkiZahn E, 2019; Turi S, 2019) and thoracic procedures (three studies: Costa F, 2019; Meijer F, 2018; Rispoli M, 2018).

The most frequent lockout interval was 20 min in 12 studies evaluating SSTS 15 mcg. In other papers, evaluating SSTS $30 \mathrm{mcg}$ lockout intervals were not reported, except for Hutchins JL 2017 (minimum 60-min redosing interval).

In ten studies (Costa F, 2019; Dransart C, 2018; Jove M, 2015; Leykin Y, 2019; Meijer F, 2018; Minkowitz HS, 2017; Pogatzki-Zahn E, 2019; Rispoli M, 2018; Scardino M, 2018; Turi S, 2019), the cumulative dosage of SSTS at $24 \mathrm{~h}$ after surgery was reported. The mean dose of sufentanil was $190.74( \pm 77.07) \mathrm{mcg}$. Other papers considered different intervals (Hutchins $J L, 2017$; Miner JR 2018) or not reported the cumulative dose of SSTS. Figure 2 displays SSTS consummation during pain treatment.

\section{Pain Intensity}

Different investigators recorded this outcome on different scales and at different intervals. We normalized all NRS to a 0-10 range (see Fig. 3). The majority of authors reported pain intensity between 12 and $24 \mathrm{~h}$ after surgery. One study, Miner JR 2018, reported NRS at 2 h. Pain intensity over the first $24 \mathrm{~h}$ was reported in 12 studies, which involved 2327 patients with 1844 in the SSTS group. All participants in SSTS group reported NRS $\leq 4$ within $24 \mathrm{~h}$ after surgery. Only one trial, Van Deen DE 2018, recorded NRS at $12 \mathrm{~h}$ of 5 and at $24 \mathrm{~h}$ of 4.5 . It is important to point out that this is the highest pain score recorded among patients treated with SSTS. At $48 \mathrm{~h}$ of treatment, all participants showed $\mathrm{NRS} \leq 4$

Three RCT (Lakshman S, 2016; Melson TI, 2014; Minkowitz HS, 2017) reported timeweighted summed pain intensity difference to baseline (SPID) over 12 or $24 \mathrm{~h}$. These studies involved 679 participants with 391 in the SSTS group and 288 in the control group. Participants in the SSTS group reported higher SPID values than those in the control group.

General anesthesia was used for most surgical procedures. Regional or local anesthesia was used in six studies (Jove M, 2015; Meijer F, 2018; Pogatzki-Zahn E, 2019; Rispoli M, 2018; Scardino M, 2018; Van Deen DE, 2018). Pain medication with opioids and non-opioids intraoperatively and/or early postoperatively was often administered before initiating the SSTS. A paper (Costa $F, 2019)$ reported the use of intravenous preemptive analgesia. Three studies (Hutchins $J L$, 2017; Lakshman S, 2016; Miner JR, 2018) did not reported data concerning pain medication.

Ten studies (Hutchins JL, 2017; Jove M, 2015; Leykin Y, 2019; Meijer F, 2018; Melson TI, 2014; Miner JR, 2018; Minkowitz HS, 2017; Ringold FG, 2015; Rispoli M, 2018; Scardino M, 2018) reported the use of rescue medication if analgesia with SSTS was insufficient. A total of 112 participants in seven studies required rescue medication (e.g., IV morphine, oral morphine, oral oxycodone, acetaminophen, ketorolac). In Rispoli M 2018, a patient reported severe pain and a single-shot para-vertebral block was performed.

\section{Patient Satisfaction}

Patient satisfaction results were presented as different degrees subjective satisfaction levels. We normalized all to "satisfied/not satisfied". 


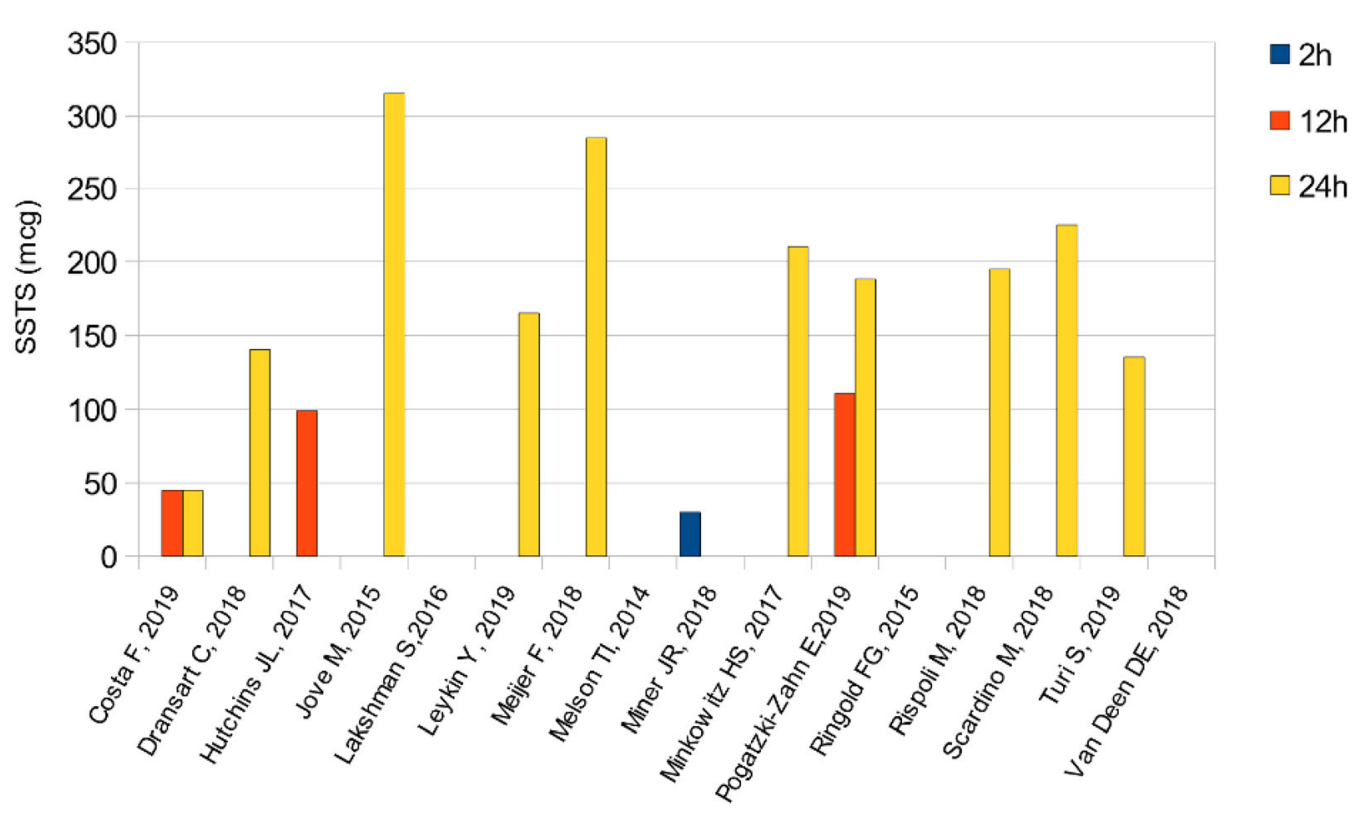

Fig. 2 Cumulative dosage of sufentanil sublingual

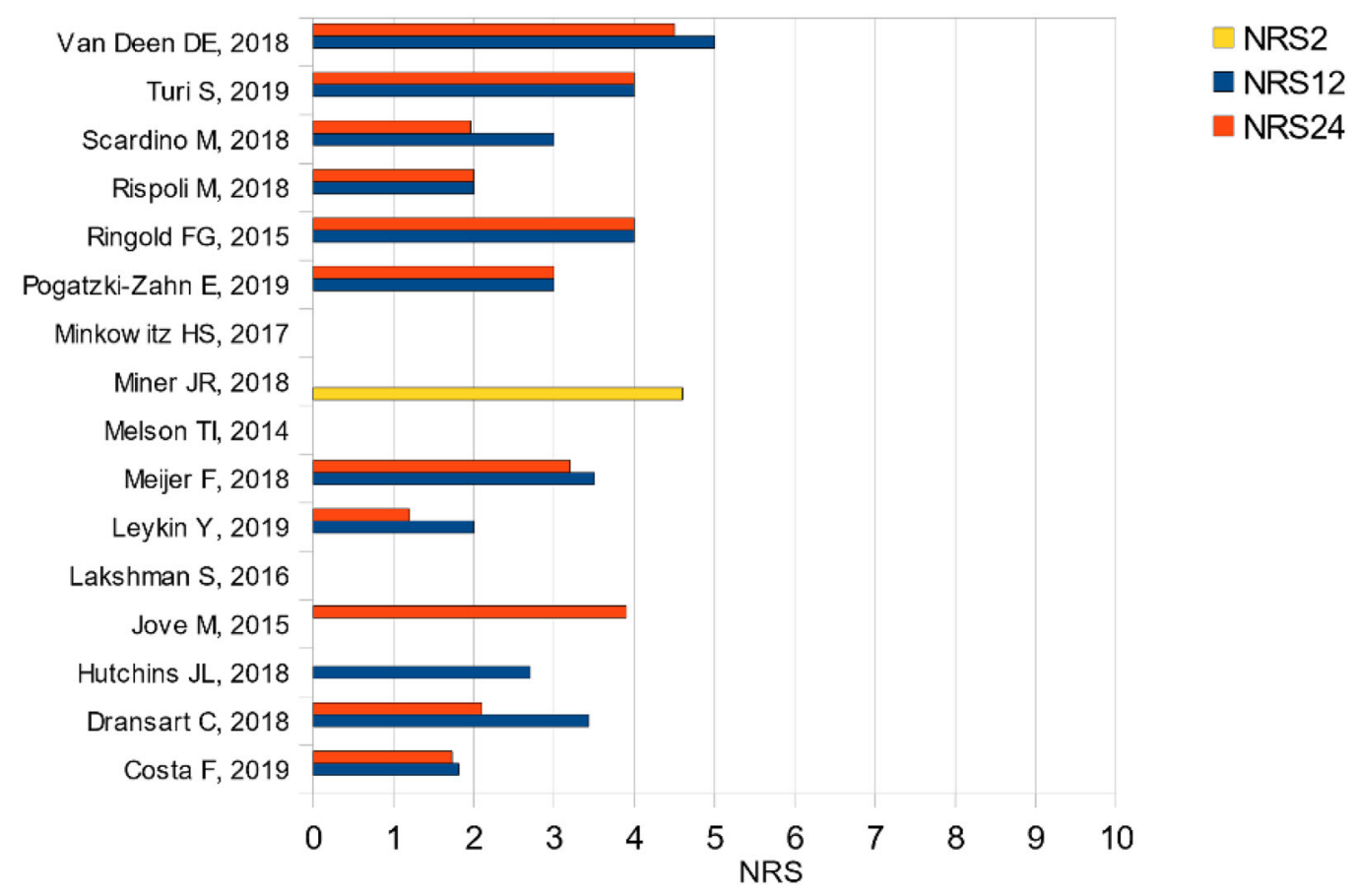

Fig. 3 Pain intensity evaluated at 2, 12, and $24 \mathrm{~h}$

Thirteen studies were available for analysis of satisfaction (see Fig. 4).

\section{Adverse Events (AEs)}

An adverse event is defined as any undesirable experience associated with the use of a medical product in a patient. A total of 958 AEs were 
Table 2 Studies characteristics

\begin{tabular}{|c|c|c|c|c|c|}
\hline References & Study & Sites & No. & Type of surgery & $\begin{array}{l}\text { SSTS } \\
(\mathbf{m c g})\end{array}$ \\
\hline Costa [9] & OS & 1, Italy & 40 & Video-assisted thoracoscopy (VATS) & 15 \\
\hline $\begin{array}{l}\text { Dransart } \\
\quad[10]\end{array}$ & $\begin{array}{l}\text { CT SSTS vs. IV } \\
\text { PCA } \\
\text { (morphine) }\end{array}$ & 1, Belgium & 80 & Lumbar laminectomy and discectomy & 15 \\
\hline $\begin{array}{l}\text { Hutchins } \\
\text { [11] }\end{array}$ & $\mathrm{CT}$ & 9, US & 140 & $\begin{array}{l}\text { Abdominal (e.g., laparoscopic or open-abdominal) and } \\
\text { orthopedic (e.g., knee or hip replacement, } \\
\text { bunionectomy) surgery }\end{array}$ & 30 \\
\hline Jove $[12]$ & $\begin{array}{l}\text { RCT } \\
\text { SSTS vs. PT }\end{array}$ & 34 , US & 315 & Hip or knee replacement & 15 \\
\hline $\begin{array}{l}\text { Lakshman } \\
\text { [13] }\end{array}$ & $\begin{array}{l}\text { RCT } \\
\text { SSTS vs. PT }\end{array}$ & $\begin{array}{l}\text { Multicenter } \\
\text { (?) }\end{array}$ & 107 & $\begin{array}{l}\text { Outpatient abdominal surgical procedures (e.g., } \\
\text { abdominoplasty, open tension-free inguinal }\end{array}$ & 30 \\
\hline Leykin $[14]$ & OS & 2, Italy & 42 & Open gynecological surgery (pfannenstiel incision) & 15 \\
\hline Meijer $[15]$ & OS & 5, & 280 & $\begin{array}{l}\text { Abdominal surgery (e.g., laparoscopic colon or rectum } \\
\text { resection), orthopedic (e.g., knee replacement surgery) } \\
\text { and other surgery (e.g., mastectomy, vascular surgery, } \\
\text { plastic surgery, thoracic surgery, or hernia correction) }\end{array}$ & 15 \\
\hline $\begin{array}{l}\text { Melson } \\
{[16]}\end{array}$ & $\begin{array}{l}\text { RCTSSTS vs. } \\
\text { IV PCA } \\
\text { (morphine) }\end{array}$ & 26, US & 177 & $\begin{array}{l}\text { Open abdominal (including laparoscopic-assisted open } \\
\text { abdominal procedures) or orthopedic (total knee or hip } \\
\text { replacement) surgery }\end{array}$ & 15 \\
\hline Miner $[17]$ & $\mathrm{CT}$ & 3 , US & 76 & Trauma or injury & 30 \\
\hline $\begin{array}{l}\text { Minkowitz } \\
\qquad[18]\end{array}$ & $\begin{array}{l}\text { RCT } \\
\text { SSTS vs. PT }\end{array}$ & 4, US & 107 & $\begin{array}{l}\text { Abdominoplasty, open tension-free inguinal hernioplasty, } \\
\text { or laparoscopic abdominal surgery }\end{array}$ & 30 \\
\hline $\begin{array}{l}\text { Pogatzki- } \\
\text { Zahn } \\
{[19]}\end{array}$ & OS & 10, Germany & 341 & $\begin{array}{l}\text { Spondylodesis, nephrectomy, bone surgery, colectomy, } \\
\text { hernia repair, hysterectomy with or without } \\
\text { adnexectomy, prostatectomy, spinal decompression, hip } \\
\text { replacement }\end{array}$ & 15 \\
\hline $\begin{array}{l}\text { Ringold } \\
{[20]}\end{array}$ & $\begin{array}{l}\text { RCTSSTS vs. } \\
\text { PT }\end{array}$ & 13 , US & 115 & $\begin{array}{l}\text { Open abdominal surgery (including open abdominal } \\
\text { surgeries that were laparoscopic assisted, such as partial } \\
\text { colectomies) }\end{array}$ & 15 \\
\hline Rispoli $[21]$ & OS & 1, Italy & 16 & Video-assisted thoracoscopic surgery lung resection & 15 \\
\hline $\begin{array}{l}\text { Scardino } \\
\quad[22]\end{array}$ & $\begin{array}{l}\text { OSSSTS vs. } \\
\text { cFNB }\end{array}$ & 1, Italy & 95 & Unilateral total knee replacement & 15 \\
\hline Turi $[23]$ & OS & 1, Italy & 308 & Major laparoscopic abdominal and gynecological surgery & 15 \\
\hline
\end{tabular}


Table 2 continued

\begin{tabular}{llllll}
\hline References & Study & Sites & No. & Type of surgery & $\begin{array}{l}\text { SSTS } \\
(\mathbf{m c g})\end{array}$ \\
\hline $\begin{array}{l}\text { Van Deen } \\
{[24]}\end{array}$ & CT & 1, & 72 & Total knee arthroplasty & 15 \\
\hline
\end{tabular}

$O S$ observational study, $C T$ clinical trial, $R C T$ randomized controlled trial

recorded. A study, Lakshman $S$ 2016, did not reported the number of AEs. The most frequently reported AEs were nausea, vomiting, and PONV (postoperative nausea and vomiting), headache, and oxygen desaturation (see Table 3 and Fig. 5). Most studies did not specify the timing of adverse events.

\section{Nausea, Vomiting, and PONV}

Nausea was the most frequent AE (492 events, $51 \%$ of AEs), following by vomiting and PONV. In nine studies (Dransart C, 2018; Jove M, 2015; Leykin Y, 2019; Meijer F, 2018; Ringold FG, 2015; Rispoli M, 2018; Scardino M, 2018; Turi S, 2019; Van Deen DE, 2018), prophylaxis was administered; in the other studies, prescription of antiemetic drugs was missed or not reported.

\section{Headache}

The incidence of headache was reported in six studies (Hutchins JL, 2017; Jove M, 2015; Lakshman S, 2016; Melson TI, 2014; Minkowitz HS, 2017; Turi S, 2019) and a total of 55 cases were reported. Only in one study, Minkowitz HS 2017, acetaminophen was administered to treat headache.

Respiratory depression In all studies, oxygen saturation was considered critical if it could not be maintained more than $95 \%$ with or without supplemental oxygen. Moreover, a respiratory rate of less than 8 breaths/min was alarming. Eight studies (Hutchins JL, 2017; Jove M, 2015; Meijer F, 2018; Melson TI, 2014; Miner JR, 2018; Pogatzki-Zahn E, 2019; Ringold FG, 2015; Turi S, 2019) reported data for respiratory depression. A total of 54 cases of reduced oxygen saturation were documented.
Dizziness The incidence of dizziness was evaluated in seven studies (Hutchins $J L, 2017$; Melson TI, 2014; Minkowitz HS, 2017; PogatzkiZahn E, 2019; Ringold FG, 2015; Scardino M, 2018). A total of 41 cases were reported.

\section{Pruritus}

A total of 37 cases were reported in four studies (Jove M, 2015; Melson TI, 2014; Minkowitz HS, 2017; Ringold FG, 2015). In two studies, Jove $M$ 2015 and Ringold FG 2015, pruritus was statistically higher in the SSTS versus placebo group (4.7 vs. 0\%).

\section{Constipation}

Two studies (Jove M, 2015; Melson TI, 2014) reported constipation for a total of 35 AEs.

\section{Others}

Hypotension was reported in three studies (Jove M, 2015; Melson TI, 2014; Minkowitz HS, 2017) for a total of 28 AEs. Melson TI 2014 reported four cases of orthostatic hypotension. A total of 28 cases of somnolence and insomnia were reported in three studies (Jove M, 2015; Miner JR, 2018; Minkowitz HS, 2017). Confusional state or sedation occurred 16 times in three studies (Jove M, 2015; Meijer F, 2018; Melson TI, 2014). Others AEs were dyspepsia (Melson TI, 2014), itching (Leykin $Y, 2019$ ), anxiety (Ringold $F G, 2015$ ), urinary retention (Melson TI, 2014), delirium (Meijer F, 2018), erythema (Scardino M, 2018), hypertension (Ringold $F G, 2015$ ) and pyrexia (Ringold FG, 2015). 


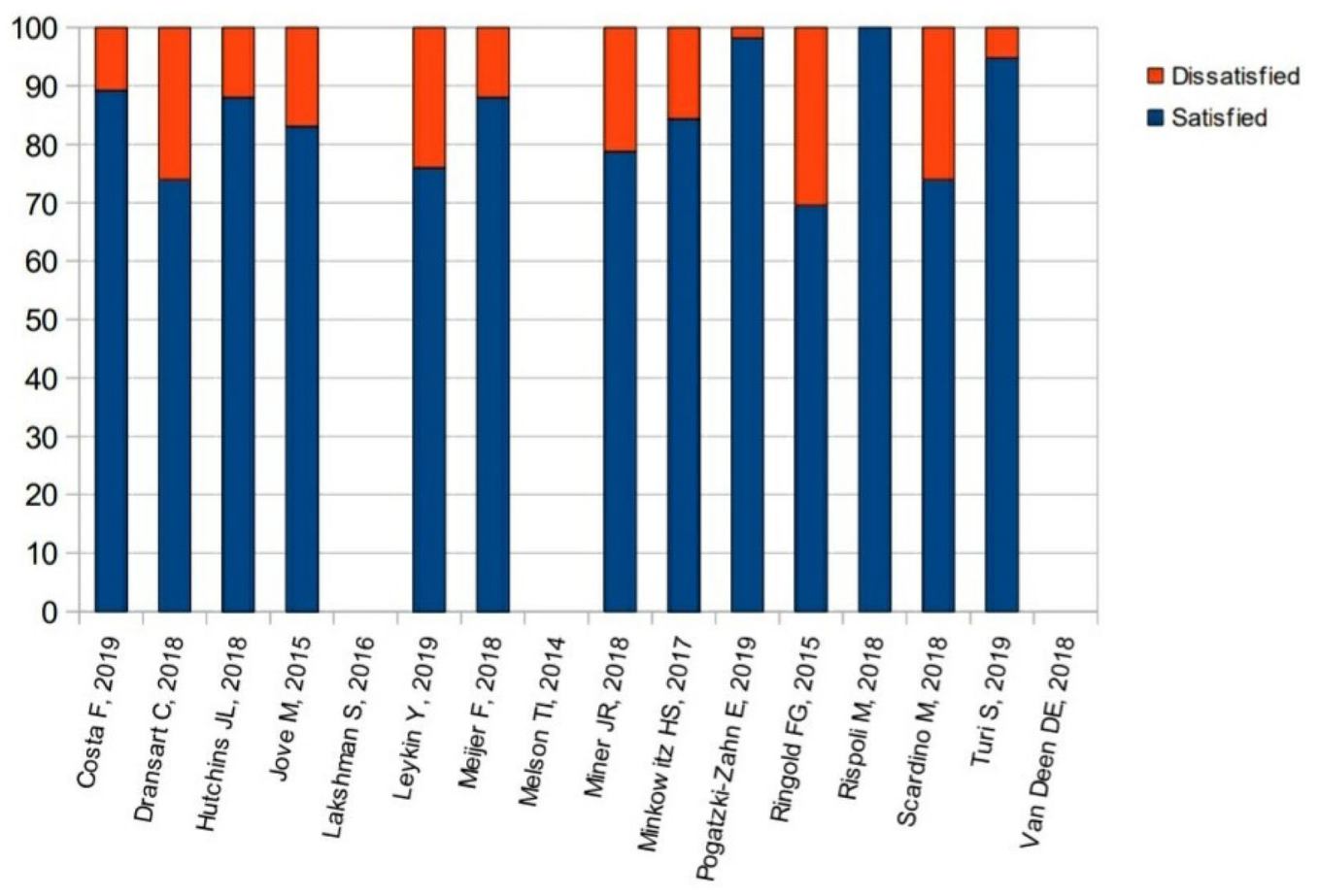

Fig. 4 Patient satisfaction

\section{Serious Adverse Events (SAEs)}

Eight studies reported data related to serious adverse events. A total of 35 SAEs were reported among patients treated with SSTS; only 17 were considered related to treatment: oxygen saturation decreased, sinus tachycardia, and confusional state from Jove M 2015; three PONV from Leykin Y 2019; one report of angina pectoris from Miner JR 2018; bradycardia, oxygen desaturation, low respiratory rate, and sopor from Pogatzki-Zahn E 2019; respiratory depression and nausea/vomiting from Turi S 2019. Among all patients receiving SSTS, there was no death considered related to treatment.

\section{Withdrawals Due to Adverse Events or Lack of Efficacy}

A total of 233 participants (10\%) withdrew from 12 studies. Twelve studies reported on withdrawals due to adverse events, lack of efficacy, or others. A total of 80 withdrawals (34\%) due to adverse events were reported from eight studies (Hutchins JL, 2017; Jove M, 2015; Leykin Y, 2019; Melson TI, 2014; Pogatzki-Zahn E, 2019;
Ringold FG, 2015; Turi S, 2019; Van Deen DE, 2018).

Withdrawals due to lack of efficacy were reported for nine studies (102 participants, 43\%) (Hutchins JL, 2017; Jove M, 2015; Melson TI, 2014; Miner JR, 2018; Minkowitz HS, 2017; Pogatzki-Zahn E, 2019; Ringold FG, 2015; Rispoli M, 2018; Turi S, 2019).

Fifty-one participants withdrew from seven studies (Dransart C, 2018; Melson TI, 2014; Miner JR, 2018; Minkowitz HS, 2017; Pogatzki-Zahn E, 2019; Ringold FG, 2015; Van Deen DE, 2018) due to other reasons.

\section{DISCUSSION}

Sufentanil acts selectively at the $\mu$-opioid receptor to produce analgesia. It is one of the most potent opioids used in clinical practice. Sufentanil has a potency 7-10 times greater than that of fentanyl and 500-1000 times greater than that of morphine, but a therapeutic index markedly higher than that of fentanyl, morphine, and other opioids [25]. 
Table 3 Number of adverse events (AEs)

\begin{tabular}{lr}
\hline AEs & No. \\
\hline Anxiety & 2 \\
Confusion state/sedation & 16 \\
Constipation & 35 \\
Delirium & 1 \\
Dizziness & 41 \\
Dyspepsia & 6 \\
Erythema & 1 \\
Headache & 55 \\
Hypertension & 1 \\
Hypotension & 28 \\
Insomnia & 13 \\
Itching & 3 \\
Nausea & 492 \\
Orthostatic hypotension & 4 \\
Oxygen desaturation & 54 \\
PONV & 15 \\
Pruritus & 40 \\
Pyrexia & 111 \\
Somnolence & 958 \\
Urinary retention & 37 \\
Vomiting & 15 \\
Total & 54 \\
\hline & 15 \\
\hline
\end{tabular}

The bioavailability of sublingual sufentanil is $60 \%$, much more than $9 \%$ of the oral route. When administered sublingually, it shows a rapid onset of action due to its high lipophilicity. Lipophilic, nonionized drug molecules have rapid uptake from sublingual tissues into the plasma as well as rapid uptake from the plasma to the $\mu$-opioid effector site in the central nervous system. It is mainly metabolized in the liver and enterocytes of the small intestines [26].

Sublingual sufentanil provided effective analgesia for adults with moderate-to-severe acute pain reducing the intensity of pain within 15-30 min after the first dose and maintaining analgesic benefit over the 2-24 h.

The sufentanil sublingual tablet system makes use of a hand-held dispenser system. The sufentanil dose of the sufentanil sublingual tablet system is fixed and only one lockout interval is available. In our review, the mean dose of sufentanil $(190.74 \pm 77.07 \mathrm{mcg})$ was lower than the maximum dose recommended. Lockout interval was the one expected for SSTS $15 \mathrm{mcg}$ (20 min) and for SSTS $30 \mathrm{mcg}(60 \mathrm{~min})$. All surgeries forecast severe acute pain. In Miner $J R$ 2018, the feasibility of using SSTS $30 \mathrm{mcg}$ for moderate-to-severe pain management in the emergency department (ED) was evaluated. Sufentanil sublingual was administered for a maximum of $72 \mathrm{~h}$ and discontinued before patients left the healthcare setting.

\section{Pain Intensity}

Pain intensity on a numeric rating scale (NRS) was lower than 4 in participants using SSTS at 12 and $24 \mathrm{~h}$, with the exception of results reported by Van Deen DE 2018, which showed a trend towards higher scores. In this study, sublingual sufentanil did not improve postoperative pain management in patients undergoing total knee arthroplasty and increased nausea compared to patients receiving oxycodone with or without dexamethasone.

We considered NRS lower than 4 as optimal cut-off point between mild and moderate pain. This cut-off was identified as the tolerable pain threshold [27].

In Miner JR 2018, SSTS $30 \mathrm{mcg}$ was evaluated over $2 \mathrm{~h}$ for managing moderate-to-severe acute pain in an ED setting. Mean pain intensity was 7.6 at baseline and decreased to 4.5 at $60 \mathrm{~min}$ and remained relatively stable (4.6) at $2 \mathrm{~h}$. Based on the experience of Cepeda MS 200 [3, 28], this decrease in NRS score is meaningful of "much/ very much" improvement.

In the RCTs reporting the summed pain intensity difference to baseline over the 12 and 24-h study period, SPID values were higher than the control group. 

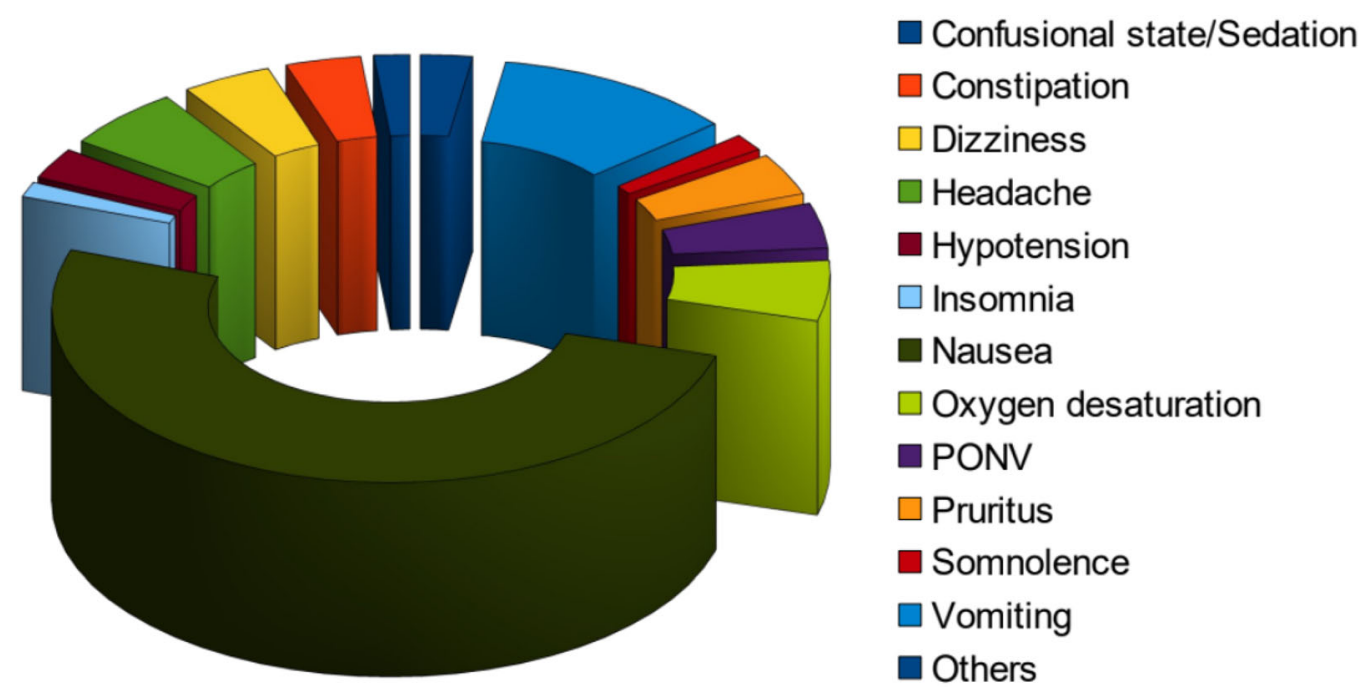

Fig. 5 Distribution of adverse events (AEs)

A total of 112 patients received upon request rescue medication if analgesia with the study medication was insufficient. Discontinuation due to inadequate analgesia occurred at low rates $(4.4 \%$ of total participants).

\section{Patient Satisfaction}

Patient satisfaction was high, with a minimum of $70 \%$ satisfaction among patients treated with SSTS. It is not surprising to find greater satisfaction with SSTS. Patients have a greater degree of autonomy which reduces fears of insufficient analgesia. Instant availability of the medication contributes to greater satisfaction with the mode of treatment. The measurement of satisfaction in trials where participants are not blinded to study arm assignment creates a potential for bias. Most of the studies in our analysis were unblinded.

\section{Safety}

The most common AEs overall for SSTS 15 and $30 \mathrm{mcg}$ were nausea, vomiting, and headache. As with any opioid, SSTS may be associated with respiratory or neuropsychiatric events, particularly in a postoperative setting where patients are recovering from anesthesia or have been administered concomitant CNS depressants, including other opioids during the surgery and during the initial stay in the recovery room. The most common respiratory $\mathrm{AE}$ was decreased oxygen saturation (5.6\% of AEs). Three patients discontinued due to respiratory AE. Neuropsychiatric events among patients treated with sufentanil were headache $(5.7 \%)$, dizziness (4.3\%), confusional state/sedation (1.7\%), somnolence $(1.6 \%)$, and insomnia (1.4\%). Discontinuation due to neuropsychiatric events occurred at low rates; specific events leading to discontinuation included confusional state and sopor. The most common gastrointestinal AEs were nausea $(51 \%)$, vomiting $(11.6 \%)$, PONV $(4.2 \%)$, and constipation (3.6\%). No patient required the use of naloxone. AEs observed in the studies were generally consistent with those associated with opioids and the postsurgical setting.

A total of 35 SAEs were reported among patients treated with SSTS; only 17 were considered related to treatment: one SAE occurred in a SSTS $30 \mathrm{mcg}$ treated patients, the others in the SSTS 15 mcg group. All events were resolved, with the study drug withdrawn.

The safety profile of sufentanil is well established based on more than 30 years of experience with sufentanil used for general anesthesia and for epidural analgesia. 


\section{Other PCAs}

Two studies (Dransart C, 2018; Melson TI, 2014) compared SSTS vs. PCA with IV morphine. Patients using SSTS reported more rapid onset of analgesia and patient and nurse ease of care and satisfaction scores were higher than IV PCA. Adverse events were similar between the two groups. No other studies have been performed to compare SSTS to other PCAs.

\section{CONCLUSIONS}

In summary, the SSTS is an important system for the management of moderate-to-severe acute pain in a hospital setting. SSTS is well tolerated, with no unexpected AEs and no clinically meaningful vital sign changes. These data confirm the safety and tolerability of the SSTS. Successful pain management resulted in a high level of acceptance of the SSTS by patients with high satisfaction for the method of pain control.

\section{ACKNOWLEDGEMENTS}

Funding. No funding or sponsorship was received for this study or publication of this article.

Authorship. All named authors meet the International Committee of Medical Journal Editors (ICMJE) criteria for authorship for this article, take responsibility for the integrity of the work as a whole, and have given their approval for this version to be published.

Authorship Contributions. Luca Gregorio Giaccari helped design the study, conduct the study, analyze the data, and write the manuscript; Francesco Coppolino helped design the study, conduct the study, and analyze the data; Caterina Aurilio helped design the study and analyze the data; Valentina Esposito helped design the study and analyze the data; Maria Caterina PACE helped design the study and analyze the data; Antonella Paladini helped design the study and analyze the data; Maria Beatrice Passavanti helped design the study and analyze the data; Vincenzo Pota helped design the study and analyze the data; Pasquale Sansone helped design the study, conduct the study, analyze the data, and write the manuscript.

Disclosures. Luca G. Giaccari, Francesco Coppolino, Caterina Aurilio, Valentina Esposito, Maria Caterina Pace, Antonella Paladini, Maria Beatrice Passavanti, Vincenzo Pota and Pasquale Sansone have nothing to disclose.

Compliance with Ethics Guidelines. This article is based on previously conducted studies and does not contain any studies with human participants or animals performed by any of the authors.

Open Access. This article is licensed under a Creative Commons Attribution-NonCommercial 4.0 International License, which permits any non-commercial use, sharing, adaptation, distribution and reproduction in any medium or format, as long as you give appropriate credit to the original author(s) and the source, provide a link to the Creative Commons licence, and indicate if changes were made. The images or other third party material in this article are included in the article's Creative Commons licence, unless indicated otherwise in a credit line to the material. If material is not included in the article's Creative Commons licence and your intended use is not permitted by statutory regulation or exceeds the permitted use, you will need to obtain permission directly from the copyright holder. To view a copy of this licence, visit http://creativecommons.org/licenses/by$\mathrm{nc} / 4.0 /$.

\section{REFERENCES}

1. Weiser TG, Regenbogen SE, Thompson KD, et al. An estimation of the global volume of surgery: a modelling strategy based on available data. Lancet. 2008;372:139-44. 
2. Zaslansky R, Rothaug J, Chapman CR, et al. PAIN OUT: the making of an international acute pain registry. Eur J Pain. 2015;19:490-502.

3. Baratta JL, Schwenk ES, Viscusi ER. Clinical consequences of inadequate pain relief: barriers to optimal pain management. Plast Reconstr Surg. 2014;134(4Suppl2):15S-21S.

4. Apfelbaum JL, Chen C, Mehta SS, Gan TJ. Postoperative pain experience: results from a national survey suggest postoperative pain continues to be undermanaged. Anesth Analg. 2003;97:534-40.

5. Chou R, Gordon DB, de Leon-Casasola OA, et al. Management of Postoperative Pain: a Clinical Practice Guideline From the American Pain Society, the American Society of Regional Anesthesia and Pain Medicine, and the American Society of Anesthesiologists' Committee on Regional Anesthesia, Executive Committee, and Administrative Council. J Pain. 2016;17(2):131-57.

6. Moher D, Liberati A, Tetzlaff J, Altman DG, The PRISMA Group. Preferred reporting items for systematic reviews and meta-analyses: the PRISMA statement. BMJ. 2009;339:b2535.

7. Terwee CB, Mokkink LB, Knol DL. Rating the methodological quality in systematic reviews of studies on measurement properties: a scoring system for the COSMIN checklist. Qual Life Res. 2012;21(4):651-7.

8. Mokkink LB, Terwee CB, Patrick DL. The COSMIN checklist for assessing the methodological quality of studies on measurement properties of health status measurement instruments: an international Delphi study. Qual Life Res. 2010;19(4):539-49.

9. Costa F, Pascarella G, Piliego C, et al. Sufentanil sublingual tablet system (Zalviso ${ }^{\circledR}$ ) as an effective analgesic option after thoracic surgery: an observational study. Saudi J Anaesth. 2019;13(3):222-6.

10. Dransart C, De Bue P, Jamart J, et al. Sublingual sufentanil tablet system for postoperative pain relief after spinal lumbar neurosurgery. A retrospective comparison with IV morphine patientcontrolled analgesia. J Clin Anesth Pain Med. 2018;2(2):22.

11. Hutchins JL, Leiman D, Minkowitz HS, et al. An open-label study of sufentanil sublingual tablet 30 $\mathrm{mcg}$ in patients with postoperative pain. Pain Med. 2018;19:2058-68.

12. Jove M, Griffin DW, Minkowitz HS, et al. Sufentanil sublingual tablet system for the management of postoperative pain after knee or hip arthroplasty: a randomized placebo-controlled study. Anesthesiology. 2015;123(2):434-43.
13. Lakshman S, Minkowitz H, Melson T, Leiman D. Abstract: safety and efficacy of sufentanil sublingual $30 \mathrm{mcg}$ tablets for the treatment of acute pain following outpatient abdominoplasty. Plast Reconstr Surg Glob Open. 2016;4(9 Suppl):58-9.

14. Leykin Y, Laudani A, Busetto N, et al. Sublingual sufentanil tablet system for postoperative analgesia after gynecological surgery. Minerva Med. 2019;110:209-15.

15. Meijer F, Cornelissen P, Sie C, et al. Sublingual sufentanil for postoperative pain relief: first clinical experiences. J Pain Res. 2018;11:987-92.

16. Melson TI, Boyer DL, Minkowitz HS, et al. Sufentanil sublingual tablet system vs intravenous patient-controlled analgesia with morphine for postoperative pain control: a randomized, activecomparator trial. Pain Pract. 2014;14(8):679-88.

17. Miner JR, Rafique Z, Minkowitz HS, DiDonato KP, Palmer PP. Sufentanil sublingual tablet $30 \mathrm{mcg}$ for moderate-to-severe acute pain in the ED. Am J Emerg Med. 2018;36(6):954-61.

18. Minkowitz HS, Leiman D, Melson T, et al. Sufentanil sublingual tablet $30 \mathrm{mcg}$ for the management of pain following abdominal surgery: a randomized, placebo-controlled, phase-3 study. Pain Pract. 2017;17:848-58.

19. Pogatzki-Zahn E, Kranke P, Winner J, et al. Realworld use of the sufentanil sublingual tablet system for patient-controlled management of acute postoperative pain: a prospective noninterventional study. Curr Med Res Opin. 2019;30:1-8.

20. Ringold FG, Minkowitz HS, Gan TJ, et al. Sufentanil sublingual tablet system for the management of postoperative pain following open abdominal surgery: a randomized. Placebo-Controlled Study. Reg Anesth Pain Med. 2015;40:22-30.

21. Rispoli M, Fiorelli A, Nespoli MR, et al. Sufentanil sublingual tablet system for the management of postoperative pain after video-assisted thoracic surgery: a preliminary clinical experience. J Cardiothorac Vasc Anesth. 2018;32(3):e61-3.

22. Scardino M, D'Amato T, Martorelli F, et al. Sublingual sufentanil tablet system Zalviso ${ }^{\circledR}$ for postoperative analgesia after knee replacement in fast track surgery: a pilot observational study. J Exp Ortop. 2018;5:8.

23. Turi S, Deni F, Lombardi G, et al. Sufentanil sublingual tablet system (SSTS) for the management of postoperative pain after major abdominal and gynecological surgery within an ERAS protocol: an observational study. J Pain Res. 2019;12:2313-9. 
24. van Veen DE, Verhelst CCWM, van Dellen RT, Koopman J. Sublingual sufentanil (Zalviso) patientcontrolled analgesia after total knee arthroplasty: a retrospective comparison with oxycodone with or without dexamethasone. J Pain Res. 2018;14(11): 3205-10.

25. Mather LE. Opioids-a pharmacologist's delight! Clin Exp Pharmacol Physiol. 1995;22(11):833-6.

26. van de Donk T, Ward S, Langford R, Dahan A. Pharmacokinetics and pharmacodynamics of sublingual sufentanil for postoperative pain management. Anaesthesia. 2018;73:231-7.

27. Gerbershagen HJ, Rothaug J, Kalkman CJ, Meissner W. Determination of moderate-to-severe postoperative pain on the numeric rating scale: a cut-off point analysis applying four different methods. Br J Anaesth. 2011;107(4):619-26.

28. Cepeda MS, Africano JM, Polo R, Alcala R, Carr DB. What decline in pain intensity is meaningful to patients with acute pain? Pain. 2003;105:151-7. 